appearances are all accounted for by the gradual stretching and straining of a myopic eye."

I am inclined to regurd cases of uncontrollable hæmorrhage from the cord in newly born children as instances of hæmophilia. It is true that in most of these cases one may fail to obtain a history of heredity ; but is heredity, after all, absolutely required to constitute the disease? In most cases it is present, and forms a valuable point in the diagnosis, but whether really essential is another thing. Take the following case, which happened in the practice of a medical friend a few months ago:- A child is born at full time; it is plump, bealthy-looking, and cries lustily. The cord is carefully tied and separated, and the child is given to the nurse. Before leaving the room the doctor has his attention drawn to the fact that the child is bleeding at the umbilicus. The cord is carefully examined, but exhibits nothing unusual. An additional ligature is placed around it and firmly secured. A fow hours after this the nurse examines the child, and, finding its under-garments soaked with blood, the doctor is again sent for. Additional ligatures and hæmostatics are applied, but they are as nothing. The child dies from bleeding by the cord, unable to be checked. If the disease here is not hæmophilia, it must be something closely akin to it.

So far as the pathology of the disease is concerned, I believe the state of the blood and bloodvessels and a defective control-action on the part of the vaso-motor centres are the important factors in its causation. When the bleeding first commences there is a slight attempt at clotting, but it is never complete, and the longer the blood trickles the paler and more watery it becomes. To the plausible theory of Resal, that the subjects of hæmophilia possess an increased power of making blood, and that in them hæmorrhages occur amongst those capillaries which are thinnest, I cannot subscribe. My experience is that while plethora precedes the spontaneous hæmorrhages, hæmophiliacs recover extremely slowly from them. Such people feel exhausted for weeks it may be, and their pallor is long maintained. It seems to me that they nave best health when pale. That a blood condition acts in some way or another as a cause we must admit, judging from the effects produced in other diseases where the blood is altered. In purpura and scurvy hæmorrhages are frequent; in some forms of anæmia and in certain diseases of the spleen a tendency to bleed is frequently noticed. I have known internal hæmorrhage in leukæmia prove fatal, and in a case of mitral stenosis and regurgitation in an anæmic young lady I have seen the incision of a gumboil followed by an alarmingly persistent hæmorrhage; the oozing lasting for days, in spite of plugging and strapping the jaws. In thesecases of uncontrollable hæmorrhage, in which there is no hereditary history of bleeding, I am inclined to think that we have the thin-walled condition of the bloodvessels and the watery state of the blood met with in hæmophilia, and that it only requires the other factor, an inactive vaso-motor centre, to complete it. ${ }^{1}$ In favour of the blood condition as a cause I would submit this, since I have noticed it again and again: Once the blood has undergone the marked alterations met with in leukæmia, it will be found that injuries which had been received years before the illness began bled but normally, and were easily restrained; but that slighter injuries received during the illness are followed by hæmorrhages slightly excessive and difficult to check. The healthy stimulus to the vaso-motor centre is healtby blood; alter the blood, and you either have its function increased, as in Bright's disease, or lowered, as, I believe, in hæmophilia. Everybody regards hæmophilia as most distinctly hereditary, and what does that mean? I take it to mean that during intra-uterine life the development of the cardio-vascular system is in some way or other interfered with, owing to the transmission of some ancestral peculiarity, the result of which is that not only is the blood itself altered and the tubes which carry it, but the nerve centres, which in later days regulate the distribution of the blood (states of dilatation and contraction of the arteries, the movements of the heart, and which must be therefore all closely associated together in their development), never reach a state of perfection. Complete control over the arteries and capillaries is therefore never the function of the vaso-motor centre in hæmophilia, and that this is the case is shown by the

1 On microscopical examination, I find the muscular fibres of the heart of $\mathrm{P}$ - smaller than those of a man of his age, but healthy. The aorta we guite bealthy. syhygmographic tracings. There is low arterial tension. Hence, when bleeding occurs the arteries do not contract sufficiently upon their contents owing to a want of proper impulses from the vaso-motor centre. I know not why the gums are the most usual seat of hæmorrhage in these cases unless it depend upon the rich vascular supply of their mucous membrane and the scanty support to the walls of the vessels-membranes, too, which are exposed to variations of atmospheric pressure and to all kinds of injury received during mastication.

Newcastlo-on.Tyne.

\section{SUCTION OF THE MALE URETERS.}

BX E. HURRY FENWICK, F.R.C.S.,

ABSISTANT-SURGEON TO THE LONDON HOSPITAL; SURGEON AYD PATHOLOGIST TO ST. PETER'S HOSPITAL.

BEFORE we attempt to excise a kidney, it is obviously of the highest importance to ascertain the existence and the working capacity of its fellow gland. Upon the capacity of the latter to bear the double burden depends the advisam bility of the proposed nephrectomy. Now, the stress resistance of a kidney can only be accurately gauged by a rigid examination of its secretion; and further, that secretion must be obtained directly from the fountain head; it must not be contaminated by the admixture of urine flowing from its diseased companion. The problem of obtaining urine direct from either of the male ureters without such admixture-for Hegar, Grünfeld, Newman, Pawlik, and Warnots

FIG. 1.

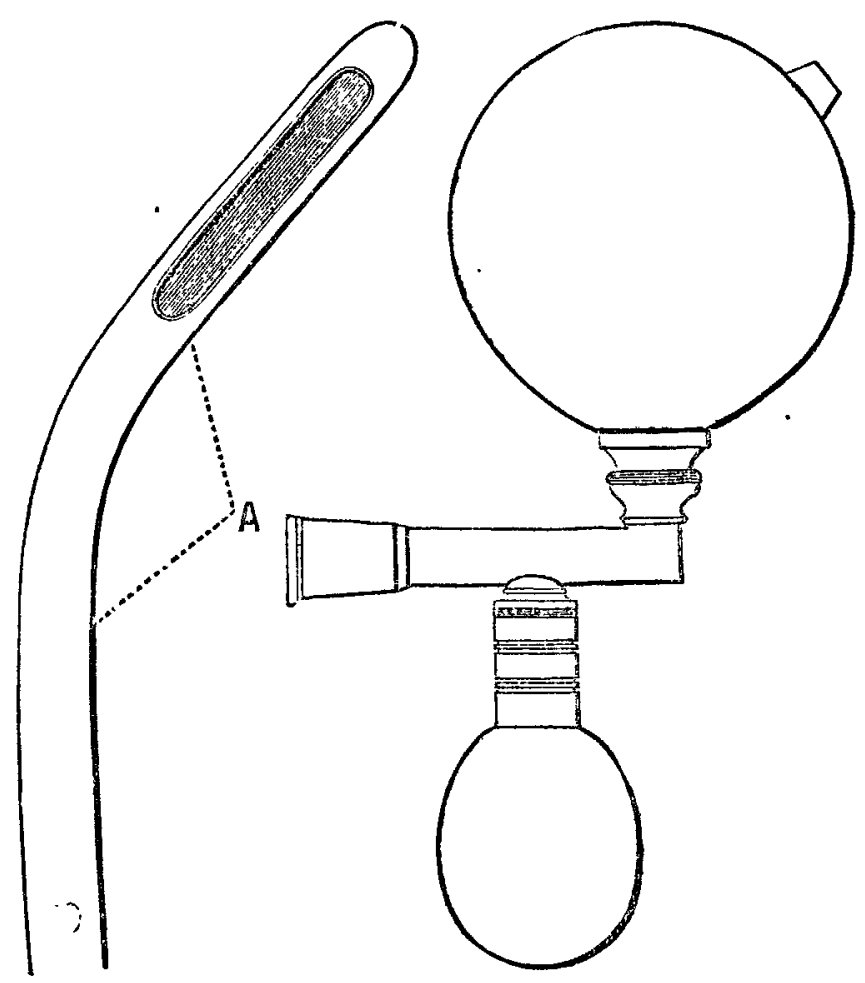

Right-sided aspirating catheter with lateral eye ; end piece, to which elastic ball and glass bottle are affixed. $A$, the measured angle.

have shown how readily the female ureters may be isolated and catheterised-is as difficult as it is important. The labour expended upon the question is as yet unproductive, for the instruments, operations, and suggestions of Tuchmann, Silbermann, Ebermann, Weir, Sands, Glück, Harrison, and others are lacking - some in simplicity, some in safety, most in success. The instrument I would submit to the profession carries out, though perhaps indifferently, what I believe to be the only feasible method for engaging and tapping the male ureters. I have had it for two years, and have proved it to be simple, easy of application, but not infallible. The principle of its action is a slight suction force which is exerted upon the ureteral orifice by means of a catheter and a small indiarubber ball. This is, I believe, an exaggerated imitation of that aspiration which the normal bladder itself exerts upon the ureters.

It will be found that the normal bladder, unless it be in ar 2 
cholera, never thoroughly contracts. Moreover, the smooth muscle wall sluggishly relaxes after its expulsive effort is over. This relaxation, at the same time that it produces a partial vacuum, diminishes the sphincteric contraction of the ureteral orifices, and any urine which may have collected in those passages is partially propelled by the vis a tergo of the circular muscle of the ureters and partially sucked by gravity and this negative pressure into the bladder. The aspirator consists of a small elastic ball and an oval glass bottle (see Fig. 1), which can be affixed to the end of a specially curved catheter, which latter is furnished with an elongated laterally placed eye. There are two catheters, one for each ureter. The bladder is first emptied and the catheter introduced. When it has fully entered, it is steadied and rotated over at the same time by the finger and the thumb, to the right or the left side according as the right or left ureter has to be engaged. The laterally placed eye will now be exactly over the ureteral orifice, for the angle $A$ (Fig. 1) is the same as the normal angle which the outer side of the trigone builds with the long axis of the urethra. Fig. 2 shows the instrument in place. Pressure of the right hand upon the elastic ball empties it of its air, and its stem is then affixed to the end

FIG. 2 ,

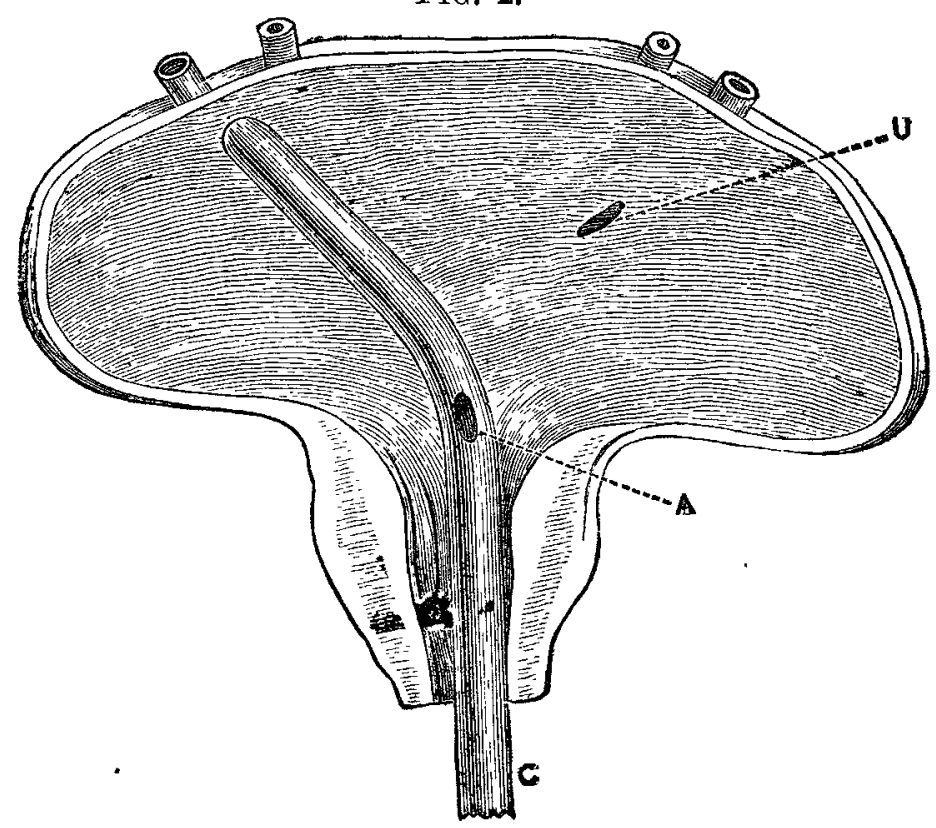

c, Right-sided aspirator in position. $\mathrm{u}$, Left ureteral orifice.

a, Opening to receive urine from ureter.

of the catheter and the ball gradually released. The air in the catheter is correspondingly exhausted and the ureteral orifice is sucked into the eye, where it can be maintained by careful management of the ball, or by gentle counter-pressure of the finger in the rectum. In ten minutes sufficient urine will have collected in the catheter for it rarely enters the glass bottle-to admit of an examination. I have lately had this catheter double channelled, so that the urine from the disengaged ureter may enter and drain off through the orifice A (Fig. 2) into a different receptacle.

I have said that it is not infallible. Sometimes there is but one ureteral orifice, as in a case I showed at the Pathological Society (1885-86). I found the ureters in another case (Path. Soc., 1886) much displaced by the action of circumureteral tubercular inflammation. Sometimes small bunches of villoid or other growth in the region of the ureters (three cases, Path. Soc., 1886) prevent close application of the eye and mislead by tinging the secretion with blood. A 20 per cent. solution of cocaine renders this slight operation painless. I have used the instrument in differential diagnosis of the site of symptomless hæmaturia, also in withdrawing scraps of growth from the trigone, and in performing an operation upon the kidney, the details of which I hope shortly to publish. The instrument can be obtained from Mayer and Meltzer, 71, Great Portland-street.

George-street, Hanover-square.

A Cenmenarian.-On the 8 th inst., at the meeting of the North Dublin guardians, Dr. Kenny, M.P., reported the death of an inmate of the workhouse at the age of 105 years. He was a sailor at the time of the Irish rebellion of 1798 , and smoked tobrcco up to the day of his death.

\section{A NEW METHOD OF}

REMOVAL OF THE ENTIRE TONGUE BY MEANS OF THE GALVANIC (OR SIMPLE WIRE) ECRASEUR AND SCISSORS.

\section{Br FERDINAND ALBERT PURCELL, M.D., M.CH.,} SURGEON TO THE CANCTR HOSPITAI.

IN my lecture given at the Cancer Hospital on Jan. 29th I demonstrated a new method for the removal of the entire tongue and floor of the mouth-applicable for removal of one-half of the organ if necessary-and presented a series of four cases operated on last year. I have christened it the "supra-hyo-glosso-epiglottidean method," which name anatomically describes the operation. The necessity for seeking for another mode for removal of part or the whole of the tongue is not that I have relinquished operating by the Whitehead or scissors method, combined with or without the preliminary tying of the linguals, or of performing first tracheotomy with the use of Trendelenburg's apparatus as used by Mr. Barker and Professor Kocher of Bern,- but that, in my experience, it may be in exceptional cases, in operating on the tongue, especially by the scissors or Whitehead method, bleeding has been the factor most difficult to combat, and its consequent result-namely, "surgical pneumonia." "Nothing is new under the sun," as the old saying goes; nor is it so in this, for Mr. Barwell so long ago as $1879^{1}$ described his method, of which mine is the offspring; and recently I was much struck by a paper on a "Method of Controlling Bleeding during Complete or Partial Excision of Tongue" by Mr. Jordan Lloyd, of Queen's Hospital, Birmingham, ${ }^{2}$ in which he applies steps of my method for the controlling of bleeding from the linguals.

With this factor--the bleeding-it is of great importance that operations should be made easy for ordinary surgeons, and as bloodless as possible for patients whose powers have been weakened by pain, from deficient nutriment arising from difficulty of mastication and salivation, and anxiety, and who, after a severe operation, and having to submit to an absence of solid food, can be expected to bear well the loss of blood. My experience of my "supra-hyo-glossoepiglottidean method" reduces our trouble from this source without any blood loss whatever, and by which is seeured a very thorough removal of the tongue, together with the floor of the mouth and all structures down to the hyoid bone. I would recommend the surgeon, as Mr. Jordan Lloyd suggests, before attempting this procedure "to familiarise himself with the glosso-epiglottidean pouch, by palpation with an index finger introduced into its deepest part and another placed outside between the hyoid bone and the under surface of the angle and rami of the lower jaw ; this anyone can try on himself; it is surprising how little tissue intervenes between the fingers, and how distinctly the various structures in relation to this space can be identified." It is necessary after removal of the tongue to have the cavity kept well drained by means of an indiarubber drain through the supra-hyoid opening, the parts dusted inside with iodoform, and the patient fed through an œsophageal tube.

The patient having been anæsthetised, first make an incision in the neck about a quarter of an inch long in the middle line from the hyoid bone forward, only skin deep; then pass a whipcord ligature through the raphe of the tongue an inch behind its tip, to hold the organ by; gag the mouth open; introduce the left index finger well to the bottom of the glosso-epiglottidean pouch, back of root of tongue. It may be necessary at this stage, so as to make room to get well round the base of the tongue, to snip with scissors the palato-glossi muscles-viz., the anterior pillars of the fauces, as also the stylo-glossi muscles of both sides; these may require pressure-forceps to be employed, as generally some small vessels may bleed; these can be taken off when wanted out of the way. Now take, say, Wood's hernia curved needle on handle, being stout, long, and well curved, threaded with medium-sized whipcord; or the needle in place of the thread may carry the platinum wire if the surgeon intends using the galvanic écraseur. Hold the needle in the right band horizontally, its concavity turned
2 Ibid., Jan. 23rd, 18:6. 